\title{
3 A Cidade-Memória: a Salvador de A Grande Feira
}

Mirela Souto Alves*

Resumo

$\mathrm{O}$ artigo tem por objetivo entender de que forma a cidade de Salvador comparece em A Grande Feira (1961), de Roberto Pires, considerando especialmente nesse filme a sua perspectiva de enquadramento da cidade na qual vivia, bem como, talvez, a sua pretensão de eternizá-la na memória. Nossa discussão é articulada ao tema da paisagem, para entendermos a temática da geografia do cinema e a subjetividade do olhar, a partir da noção de espaço. Utilizamos esse filme não como objeto de análise fílmica, mas sim como fonte ilustrativa da nossa discussão entre cinema, memória e espaço urbano.

Palavras-chave: Cidade, Memória, Paisagem, A Grande Feira.

\section{Abstract}

The objective of this paper is to understand how the city of Salvador appears in The Great Exhibition (1961), Roberto Pires, especially considering in this film, his perspective about the city in which he lived, as well as, perhaps, his determination to eternalize it in his memory. Our discussion is conveyed to the landscape theme, in order to understand the theme of geography and the subjectivity of the appearance, from the notion of space. We use this movie, not as an object of film analysis, but rather as a source of descriptive discussion among our cinema, memory and urban space.

Key-words: City, Memory, Landscape, The Great Fair. 


\section{Introdução}

Considerando o contexto atual, marcado pela predominância da imagem e do espetáculo, necessariamente percebemos a importância que o cinema adquire nesse mundo contemporâneo, por ser a forma de arte que, surgida e desenvolvida concomitantemente ao movimento e à urbanização que sofrem as cidades, tem a possibilidade de captar a ambiência e os fatos do seu tempo, de exprimir suas angústias e seus desejos numa linguagem que é universalmente compreensível.

Com frequência, não paramos para refletir que todo esse predomínio das imagens que se apresentam em tela hoje em dia foi potencializado pelo cinema, como sabemos, o primeiro a dar movimento à imagem e que influenciou o modo de ver e pensar das pessoas ao longo do tempo. Por isso, pensar a arte cinematográfica hoje é, cada vez mais, pensar num mundo social que se tornou, ao mesmo tempo, telânico e hiperespetacular (LIPOVETSKY, 2009, p.29).

Mas não podemos pensar a grande tela e sua evolução sem pensarmos nas transformações da urbe com o aparecimento das tecnologias de comunicação. A sétima arte não teria sido possível sem a modernização da cidade, e esta, não por acaso, tornou-se palco e cenário desse espetáculo da imagem em movimento. A cidade, bem como o cinema, foi, desde cedo, reduto de sensibilidade e sociabilidade. Pertencer a uma cidade implicou formas, sempre renovadas ao longo do tempo, de representar essa cidade, fosse pela palavra, escrita ou falada, fosse pelas imagens, desenhadas, pintadas ou projetadas, que a representavam, no todo ou em parte. Às cidades reais, concretas, visuais, corresponderam outras tantas cidades imaginárias. Por isso, vale dizer que a cidade registrada pelo cinema é sempre pensada no presente, que se renova de modo sucessivo, seja através da memória, individual ou coletiva.

Nota-se, desde aqui, que as relações entre cinema, cidade e memória não são poucas e nem são curtas. Há uma proximidade muito grande entre esses três temas, que, aliás, são indissociáveis.

A sétima arte, nascida há 120 anos, e, por isso, considerada uma arte essencialmente moderna, influenciou, sem dúvida, os indivíduos na forma de ver e sentir o mundo a partir das projeções feitas sobre diversos conteúdos. Pessoas de todas as classes foram atraídas e afetadas por essa indústria- 


\section{Mirela Souto Alves}

arte que iniciou e fomentou transformações significativas na vida social atualmente potencializadas pela amplitude das produções audiovisuais

Nossa intenção é entender de que forma a cidade de Salvador aparece em A Grande Feira, constituindo-se uma cidade que denominamos cidade-memória. Articulamos essa discussão ao tema da paisagem e sua relação com a memória a partir do olhar de Roberto Pires.

O filme, lançado em 1961, é um registro urbano que aborda um episódio traumático para a cidade: a ameaça de uma empresa imobiliária de abolir a feira de Água de Meninos, hoje extinta, e a luta dos feirantes que se organizam para resistir a um futuro despejo. O marinheiro Ronny, interpretado por Geraldo Del Rey, com seus dois amores, Maria da Feira (Luiza Maranhão) e Ely (Helena Ignez), moça casada da alta sociedade, são alguns dos personagens que conduzem a narrativa. Além desses, há Ricardo (Milton Gaúcho), que é quem recebe cargas roubadas, e Chico Diabo (Antônio Luiz Sampaio), ladrão que quer colocar fogo na feira.

A Grande Feira foi um sucesso de bilheteria, levando milhares de espectadores ao cinema, que queriam ver de perto

Dossiê Cinema e Audiovisual: entre o sensível e o reflexivo

Arquivos do CMD, Volume 3, N. 1. Jan/Jul 2015 um filme que tão bem representava a Bahia. "A Grande Feira foi recorde de bilheteria nos cines Jandaia e Capri, superando na época o faturamento do clássico Ben Hur" (GUSMÃO, 2008, p. 216)

Essa obra oferece elementos suficientes para uma investigação na qual se busca analisar de que forma a cidade é construída na linguagem cinematográfica. A Grande Feira apresenta - através dos diálogos e, em paralelo, das imagens do filme, bem como da atuação dos personagens e das técnicas utilizadas no cinema, como movimento de câmera, edição, cores, planos, enquadramentos, dentre outros - elementos que, juntos, constroem uma cidade da memória. Outrossim, a obra permite uma (re)leitura da cidade a partir dos elementos simbólicos em que se cruzam o imaginário, a história e a memória. Portanto, o filme A Grande Feira explicita, a meu ver, a relação potencial entre cinema, memória e cidade.

\section{Paisagem e memória}

Discorrer sobre o tema da paisagem na proposta de estudo em questão é, a priori, dar preferência ao entendimento das imagens como fenômenos contextualizados e permeados de significados e sentidos que possibilitam a leitura e interpre- 


\section{Mirela Souto Alves}

tação do mundo. Como alerta Ferraz (2001), as imagens não se reduzem a si mesmas. Elas são fruto das relações, desejos e necessidades humanas, que se espacializam, “espaço não necessariamente geometrizável, mas possuidor de certa lógica e processos explicativos e contextualizadores dessas imagens a partir do e com o ser humano em suas relações" (FERRAZ, 2001, p.26).

Estamos falando de uma paisagem geográfica, a qual, no cinema, é trabalhada a partir de um conjunto de imagens temporais organizadas para se criar uma história, um sentido organizacional para as ações humanas sobre um espaço, o espaço geográfico. Este, portanto, tem o poder de dar significado e sentido às imagens fílmicas. Enfim, fazemos uso do conceito de paisagem não com o intuito de dizer o que vem a ser essa paisagem, mas como uma imagem, sendo a mesma passível de observações, significações e descrições por meio de uma obra fílmica que cria e recria a paisagem a partir da relação necessária e constante entre o olhar e a capacidade humana de analisar o que está vendo.

Há ainda outras contribuições acerca do conceito de paisagem, no qual destacamos Santos (1987, p. 37), que a

Dossiê Cinema e Audiovisual: entre o sensível e o reflexivo

Arquivos do CMD, Volume 3, N. 1. Jan/Jul 2015

entende como o resultado da "[...] combinação de objetos naturais e objetos fabricados, isto é, objetos sociais, e o resultado da acumulação das atividades de muitas gerações”. Assim, o autor não desconsidera os "objetos naturais", mas os coloca em relação de igualdade com os "objetos sociais" e define a paisagem como resultado de um processo histórico. Logo, "resultado de uma acumulação de tempos... representando diferentes momentos do desenvolvimento da sociedade" (SANTOS, p.38). As paisagens são construções sociais ou, como diz Schama (1996, p. 17), “obras da mente”. Para o autor,

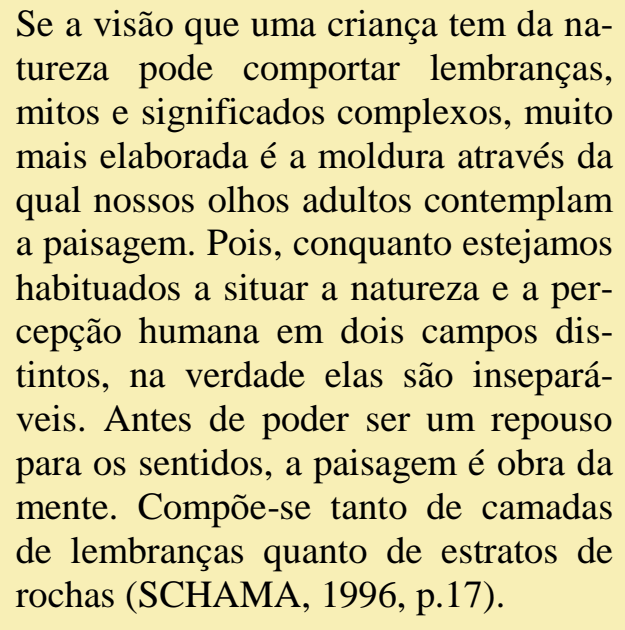

Se a visão que uma criança tem da natureza pode comportar lembranças, mais elo sicos complexós qual nossos olhos adultos contemplam a paisagem. Pois, conquanto estejamos habituados a situar a natureza e a perTom campos disrepouso mente. Compõe-se tanto de camadas de lembranças quanto de estratos de rochas (SCHAMA, 1996, p.17). 


\section{Mirela Souto Alves}

Nessa perspectiva, fica evidente que o ato de registrar um lugar, uma paisagem, pressupõe nossa presença e, junto conosco, toda a bagagem cultural que carregamos.

A paisagem não é identificada como a matéria bruta da história geológica, mas como sedimentação das relações humanas que moldam e são igualmente emolduradas pelo ambiente já carregado de significados. Ela é, sem dúvida, produto da ação humana a longo prazo, apresentando uma dimensão histórica e, por existir numa certa área da superfície da terra, apresenta uma dimensão espacial. É, por conseguinte, portadora de valores, crenças, mitos e utopias, possuindo uma dimensão simbólica. Por isso,

a paisagem nasce da experiência temporal articulada ao movimento da sensibilidade, como um projeto de experiência narrativa que concilia, na memória compartilhada, a existência do grupo compreendido na disjunção do todo da natureza (SILVEIRA, 2009, p.89).

Se considerarmos a cidade e sua relação com a paisagem, o pensamento de Farias (2011) nos é bastante significativo.
A cidade como paisagem é a memória das intervenções, mas também o lócus, o altar onde se celebram as reciprocidades e a arena das lutas que consagram ou esmagam modos de atuar sobre a lembrança e possibilitar o acesso ao conhecimento proveniente da memória. A paisagem urbana guarda na textura os jogos de poder - os confrontos e a apropriação que tecem a tela apreendida como cena legítima. Nesse sentido, a paisagem urbana consiste em uma maneira de arrumar o espaço e traduz as trajetórias na construção de hegemonias sociais, na contrapartida dos valores priorizados internos à eleição dos patrimônios que a notabiliza (FARIAS, 2011, p.201).

Tomamos emprestado de Mariza Guerra (2012, p.2) a noção de que

a memória também evoca melhor, elabora a tradução - do mundo, das pessoas, das coisas, das palavras, das imagens, dos sons, dos cheiros, da morte, dos impasses, dos desejos, das lutas, das esperanças, das paisagens.

Nesse ponto, Guerra (2012, p. 4) sugere que a memória é em si mesma audiovisual, já que o processo de rememo-

Dossiê Cinema e Audiovisual: entre o sensível e o reflexivo

Arquivos do CMD, Volume 3, N. 1. Jan/Jul 2015 


\section{Mirela Souto Alves}

ração geralmente se dá através de informações que ascendem à memória sob a forma de imagens ou de imagens mentais, que são ativadas no ato de lembrar. Logo, o tema da memória da perspectiva pela qual adotamos é um componente importante para se pensar na seleção, escolha ou enquadramentos de imagens que podem ser trabalhadas positivamente para a formação das sensibilidades e na direção do pensamento livre.

No artigo Palavra, imagem e enigma, Lucia Santaella (1992-1993) deixa evidente que toda imagem está repleta de signos que se constituem como algo que se coloca no lugar de alguma "coisa" ou então adquirindo status de linguagem, atividade esta produzida pelos homens, pois é ele o responsável por atribuir aos sinais a condição de signos ou linguagem. Essas linguagens que produzem ou que são produzidas pelos homens em suas reflexões possibilitam um encontro dos sujeitos (contemporâneos) com o que já havia sido pensado/teorizado/sentido por indivíduos pertencentes a um momento histórico anterior. Esse contato possibilita a criação e o surgimento de novas construções, interpretações e teorias, mediadas agora pela perspectiva/ótica contemporânea. Ora, a imagem não é apenas uma reprodução da "realidade", mas um outro modo de vê-la, num processo contínuo e dialógico.

Portanto, aqui, importa compreender e explicitar a relação entre o acervo cultural do cineasta e a sua peculiaridade em recriar, enquadrar a cidade, para eternizá-la ou imortalizá-la na memória. Assim sendo, visamos a reconhecer nas artes, e porque não no cinema, também um elemento paisagístico. Cabe então o questionamento: o que seriam as geografias ou paisagens de um filme?

Para Oliveira Júnior (2006), “a geografia de cinema seriam os estudos e os encontros com a dimensão espacial na qual as personagens de um filme agem”. Esse espaço é constituído pelos "locais narrativos", ou seja, os lugares (cenários e estúdios) por onde a trama do filme vai sendo ambientada, garantindo à cena uma geograficidade, moldada pela continuidade da narrativa cinematográfica que dá sentido à história. Contudo, é importante ressaltar que essa geografia produzida e arquitetada em um filme "construída pelos passos e olhares dos personagens" (OLIVEIRA JÚNIOR, 2006, não paginado), não está necessariamente ou correspondente somente à geografia da superfície da Terra.

Dossiê Cinema e Audiovisual: entre o sensível e o reflexivo

Arquivos do CMD, Volume 3, N. 1. Jan/Jul 2015 


\section{Mirela Souto Alves}

De alguma maneira, qualquer filme possui essa espacialidade da qual falamos, que é constituída de lugares, nãolugares e também territórios. Em uma obra cinematográfica, o espaço "real" é recriado, sonhado, decomposto, recortado, lembrado e "vivido como parte de uma experiência que une as histórias cotidianas, as memórias de vida e as histórias de seus personagens" (BARBOSA, 2004, p.64).

Se esse espaço é recriado, obviamente é porque existem escolhas e um caminho pessoal e emocional, que se relaciona com o meio. Mas ainda que a experiência possa ser individual - e, como nos lembra Bateson (1986), ela é sempre subjetiva -, o olhar emerge como expressão cultural, uma vez que estamos no terreno do "sensível social".

Simmel (1996 apud MALDONADO, 1996) chama a atenção para a subjetividade do olhar quando se refere a um tratamento fenomenológico do espaço. A natureza, percebida como fragmento de uma totalidade, só poderá constituir-se uma paisagem a partir do olhar que está imbuído de um "sentimento de ordem da subjetividade e da afetividade". Simmel acredita que há um estado de espírito, um sentimento pessoal, que ele denomina como a capacidade de apreender de forma sensível uma totalidade enquanto paisagem. Nesse caso,

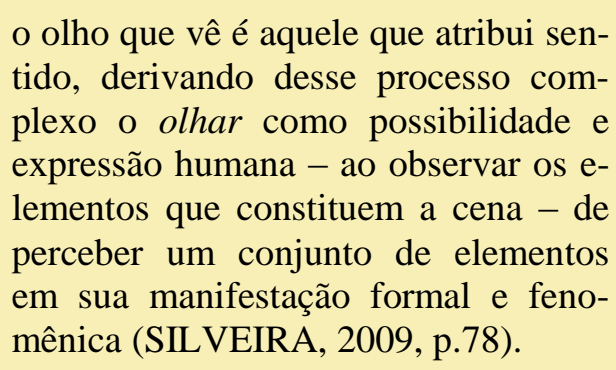

Assim, ao se revelar um fenômeno do ser, a partir da relação com a cultura, possibilita ao ser humano experimentar de maneira variada o seu vínculo com as paisagens, especialmente no que elas têm de espacialidade, que pode estar numa cidade, ecossistema, local de cultivo etc.

\section{Salvador e os olhares de Roberto Pires para uma}

\section{cidade fílmica}

Nosso foco é para A Grande Feira, obra na qual o diretor Roberto Pires faz uso da imagem da cidade (de Salvador) como paisagem na sua produção, quer dizer, seleciona ou faz um recorte de parte da cidade que ele pretende registrar.

Dossiê Cinema e Audiovisual: entre o sensível e o reflexivo

Arquivos do CMD, Volume 3, N. 1. Jan/Jul 2015 


\section{Mirela Souto Alves}

Interessa-nos saber: que cidade é essa? Como ela comparece nesse filme?

Logo nos minutos iniciais da película, antes mesmo de apareceram os créditos de abertura, já é possível notar de que lugar estamos falando. Na primeira sequência do filme, encontramos o Cuíca de Santo Amaro, de início num plano fechado e, em seguida, num plano geral, vendendo livrinhos na Cidade Baixa, embaixo do Elevador Lacerda, que é um dos símbolos mais populares e foto de cartão postal de Salvador, também conhecido como o coração da cidade e que, certamente, faz parte da memória coletiva dos indivíduos. A escolha em filmar esse ambiente certamente não foi por acaso. Numa época em que a Bahia estava sendo filmada intensamente como cenário de filmes de todos os lugares do mundo, era favorável que determinadas imagens, sobretudo as turísticas, como o Elevador, fizessem parte do filme e fossem reconhecidas pelo espectador. Quem assiste ao filme e reconhece a paisagem logo conclui que se trata de um filme sobre a capital baiana.

Mas, desde já, queremos deixar claro que não estamos analisando a obra como uma representação da cidade de Sal- vador. Aqui, nós entendemos que a intenção de Roberto Pires não foi tão somente representar a cidade tal como ela era. $\mathrm{O}$ que o diretor fez foi nos apresentar recortes de uma cidade, a partir do seu ponto de vista, da sua subjetividade. É nesse sentido que o olhar de quem registra uma imagem está relacionado ao seu percurso de formação, às suas histórias, lembranças e memórias. Essa reflexão encontra respaldo analítico nas observações de Flávio Silveira (2009, p.79),

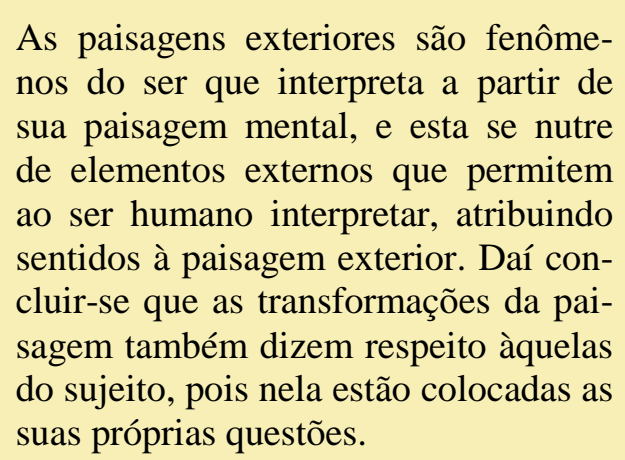

Claro está, então, que os significados atribuídos aos lugares revelam vínculos simbólico-afetivos que estão relacionados com as formas de sociabilidade e com a possibilidade de se experimentar esteticamente a relação com o lugar.

Dossiê Cinema e Audiovisual: entre o sensível e o reflexivo

Arquivos do CMD, Volume 3, N. 1. Jan/Jul 2015 


\section{Mirela Souto Alves}

Na sequência, deparamos-nos com outra paisagem da

Entrevista concedida à autora, em 23 de agosto de 2012, em Salvador-BA.

cidade no filme que nos chama a atenção (figura 1). A imagem mostra os saveiros espalhados no cais, onde um deles começa a se afastar mansamente em direção à praia de Água de Meninos. Ao longe, a cidade se apresenta em seus dois andares ligados pelo Elevador Lacerda e inúmeras ladeiras de diversas inclinações e tamanhos que serpenteiam pelas encostas, como podemos visualizar na imagem abaixo. O casario de diversas épocas e estilos se amontoam acompanhando as ladeiras e ruas, criando um presépio gigantesco. Música instrumental acompanha a cena. O saveiro continua até a praia de Água de Meninos.

Figura 1

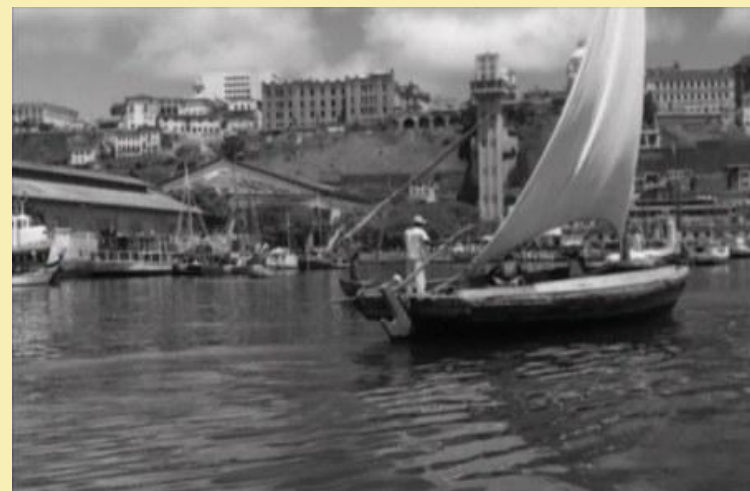

Fonte: Imagem retirada do filme A Grande Feira, de Roberto Pires.
Nesta cena, em plano geral, o diretor apresenta uma das paisagens da cidade, constituída por imagens diversas que nos mostram um pedaço de Salvador. Aqui, aparece na tela uma Salvador pacata, pacífica, uma Salvador verdadeiramente provinciana. E o fato de utilizar uma música instrumental durante a cena reforça ainda mais o lado poético que a cidade revela e, junto com ela, a visão também poética de Roberto Pires, que é, aliás, como supõe Raymundo Mendonça ${ }^{1}$, um aspecto pouco falado na história do percurso cinematográfico do cineasta. Ele diz: "Acho que a poesia da imagem no Roberto que se expressa em momentos de profunda delicadeza e sensibilidade no cinema ela é pouco falada. Em A Grande Feira, a cena do barco, a cidade passando etc. Ali, tem uma poesia da liberdade..."

Há também a paisagem da feira de Água de Meninos (figuras 2 e 3 ), local onde acontece a maior parte do enredo do filme.

Dossiê Cinema e Audiovisual: entre o sensível e o reflexivo

Arquivos do CMD, Volume 3, N. 1. Jan/Jul 2015 


\section{Mirela Souto Alves}

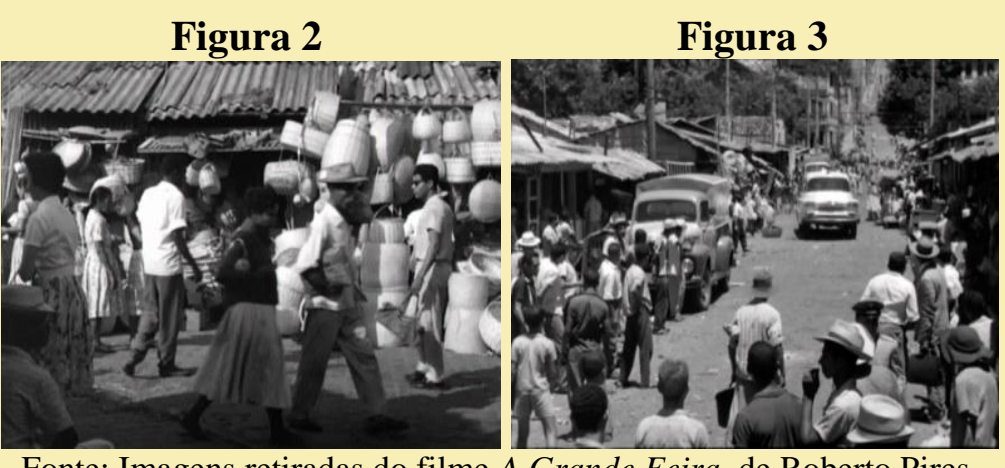

Fonte: Imagens retiradas do filme A Grande Feira, de Roberto Pires. A maioria das imagens foi gravada na própria feira

"real”, com exceção das cenas internas dos bares e barracas, que foram filmadas em estúdio. Nessas sequências, Roberto tenta mostrar a realidade de um povo que não só trabalhava, mas que morava na feira. Nas imagens, há presença de muitas pessoas e das mercadorias que eram comercializadas naquele local e até de carros, pois a camada mais rica da cidade também fazia compras ali. A nosso ver, Pires retrata ali a existência mesmo de uma outra cidade. É como se a Feira de Água de Meninos fosse uma cidade dentro d'outra que é a cidade do Salvador.

No decorrer do filme, o diretor utiliza outras imagens para mostrar a paisagem da cidade e o que há nela, como automóveis, ônibus e bondinho. Retrata uma cidade desenvolvi-

da ou que buscava o desenvolvimento, fato que era mostrado nos filmes da época por outros cineastas, já que era o contexto político e social que Salvador vivia na ocasião (figuras 4 e 5). Como Roberto Pires fazia parte daquela sociedade, nada mais natural do que expressar aspectos dessa conjuntura (que fazia parte de sua memória individual e coletiva) em determinados enquadramentos do seu filme.

Figura 4

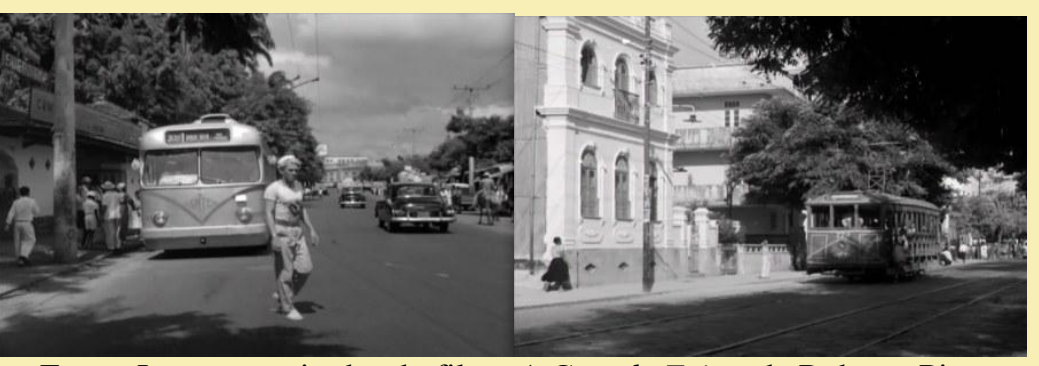

Fonte: Imagens retiradas do filme A Grande Feira, de Roberto Pires.

Não é à toa que Andréa Barbosa (2004, p. 63-64) nos acrescenta que "mais do que um conjunto de imagens, as cidades do cinema constituem parte do corpo da nossa experiência do mundo". Portanto, o percurso que tentamos traçar aqui é o operado pelo jogo no qual nossa inserção cotidiana

Dossiê Cinema e Audiovisual: entre o sensível e o reflexivo

Arquivos do CMD, Volume 3, N. 1. Jan/Jul 2015 


\section{Mirela Souto Alves}

no mundo é permeada por todas as nossas experiências sensíveis, afetivas e pela nossa memória coletiva e individual.

De todas as paisagens apresentadas em A Grande Fei$r a$, há uma, porém, que nos impacta com mais intensidade, qual seja a cena em que o sueco Rony faz um passeio de carro com Ely por vários trechos da cidade e, em seguida, um turismo de lancha. Nessas imagens (figuras 6, 7, 8 e 9), Roberto Pires faz questão de mostrar uma outra Salvador, que contrasta com a imagem registrada da feira, onde a população é pobre e, ao invés de prédios luxuosos, vê-se barracas e sobrados. Nessa sequência, enquanto dialogam, diversas paisagens são registradas ao longo da orla. O mar, algumas casas, prédios, carros, muitas árvores, pessoas andando... Em alguns instantes, o plano geral deixa nítida a paisagem com todos esses elementos, o que nos permite visualizar a imagem de um espaço completamente urbano. Em seguida, é possível avistar o Elevador Lacerda e o porto. Logo depois, uma lancha a motor em velocidade cruza a Bahia de Todos os Santos em alta velocidade. Aqui também, o diretor faz uso de música instrumental para acompanhar a cena.

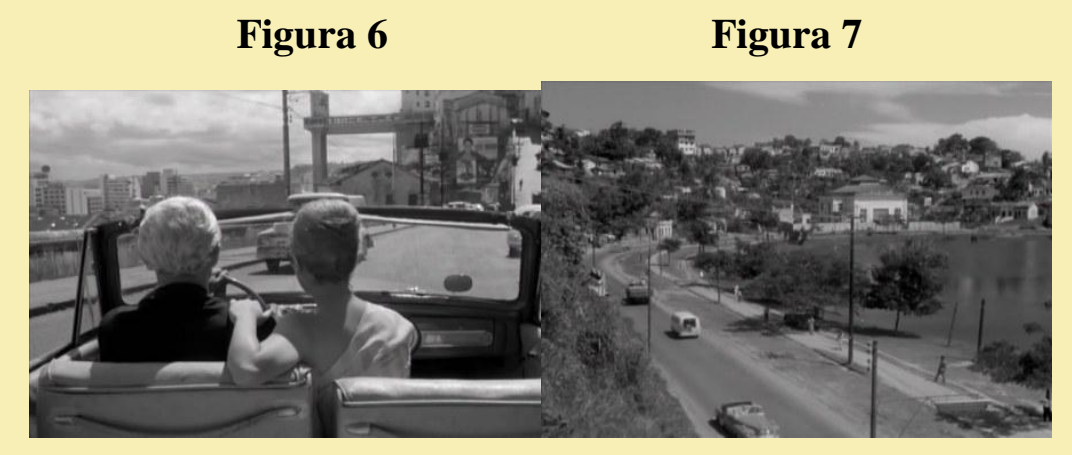

Figura 8

Figura 9

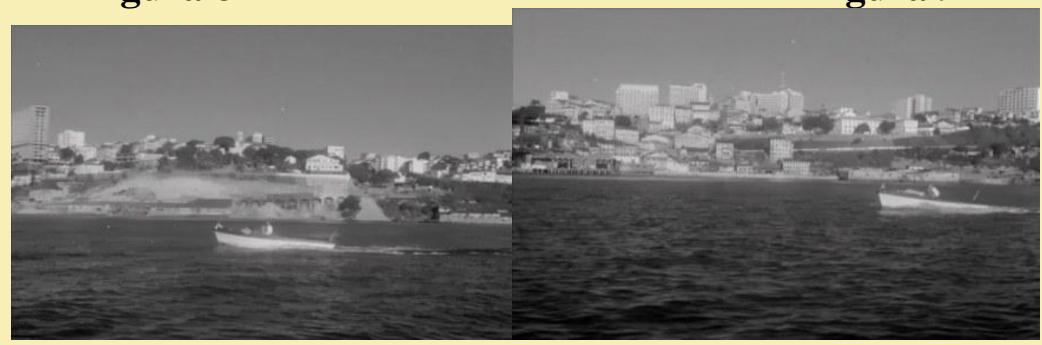

Fonte: Imagens retiradas do filme A Grande Feira, de Roberto Pires.

É nessa cena que a câmera, num plano geral, capta imagens de toda uma paisagem urbana, pertencente à classe média alta. Fora da feira, o filme cria uma cidade moderna, com ruas agitadas e policiadas, tráfego intenso, prédios altos e residências luxuosas de arquitetura moderna onde habitam os que possuem estratos mais ricos, a elite soteropolitana. Nessa vista, portanto, encontramos uma cidade romântica, a Salva-

Dossiê Cinema e Audiovisual: entre o sensível e o reflexivo

Arquivos do CMD, Volume 3, N. 1. Jan/Jul 2015 


\section{Mirela Souto Alves}

dor do amor, da poesia, do encantamento, apresentada sob o olhar de Roberto. Segundo Bernadet (1991, p.36),

Filmar então pode ser visto como um ato de recortar o espaço, de determi-

nado ângulo, em imagens, com uma

finalidade expressiva. Por isso, diz-se que filmar é uma atividade de análise.

Essas paisagens urbanas são, desse modo, lugares cujas imagens carregam uma força simbólica relacionada com o imaginário corrente da cidade de Salvador. As razões dessa relação estão na história que esse lugar protagoniza e na forma como as pessoas se apropriam dela e dos lugares, recriando-os e rememorando-os. Nas cidades do cinema, "trata-se sempre de espaço tornando-se tempo e de um tempo se tornando experiência, isto é, olhar" (COMOLLI, 1995, p.167).

\section{Considerações finais}

Ao refletirmos sobre os temas memória, cinema e cidade, verificamos que há uma relação de complementaridade entre essa tríade que, a rigor, desenvolvem-se com um vínculo de dependência. É assim, como vimos, com a sétima arte e o espaço urbano. O cinema potencializa a modernização da cidade, e esta, por sua vez, contribui sobremaneira com a evolução do cinema, pois é na ambiência urbana que ele encontra possibilidade de expressão. Já a memória permeia todo esse espaço: o cinematográfico e o espaço da cidade dita real. Afinal, como sustenta o filósofo americano Edward Casey, citado por Myrian Sepúlveda dos Santos (2003, p. 28), “não há nada no mundo que não seja mnemônico por natureza". A memória, assim, perpassa por todos os sentidos e é determinada por eles.

Nosso interesse nesse estudo foi entender de que forma a cidade de Salvador comparece no seu filme A Grande Feira (1961), considerando a sua perspectiva de enquadramento da cidade na qual vivia e a sua suposta pretensão de eternizá-la na memória. Buscamos compreender, em síntese, a forma como o cineasta Roberto Pires olhava para as paisagens da cidade de Salvador. Estas, como vimos, são construções sociais e, como lembra Schama (1996, p. 17), “obras da mente"; por isso, estão também atreladas ao tema da memória. Os recortes que fez da cidade, enquadrando-a a partir da sua subjetividade são resultado de toda a sua trajetória naquele lugar. 


\section{Mirela Souto Alves}

Assim, estamos cientes de que o cinema como um todo se constitui uma lembrança, reconstruindo com ideias e imagens atuais as vivências do passado, ambas, como bem afirmou Halbwachs (2006), relacionadas às representações coletivas estabelecidas por grupos sociais. O cinema funciona, então, concomitantemente, como meio de conservação e atualização de situações/fatos e histórias passadas, bem como meio para a rememoração.

\section{Referências}

BARBOSA, Andréa. "Ronda: espaço, experiência e memória em sete filmes paulistas dos anos 1980”. In: NOVAES, S. C. et al. Escrituras da Imagem. São Paulo: EDUSP/FAPESB, 2004.

BATESON, Gregory. Mente e Natureza: a unidade necessária. Rio de Janeiro: Francisco Alves, 1986.

BERNARDET, Jean-Claude. Brasil em Tempo de Cinema. 3. ed. Rio de Janeiro: Paz e Terra, 1978.

COMOLLI, Jean L. A Cidade Filmada. Cadernos de Antropologia e Imagem. Rio de Janeiro, n.4, 1995.
FARIAS, Edson. Ócio e Negócio: festas populares e entretenimento - turismo no Brasil, $1^{\text {a }}$ ed. Curitiba: Appris, 2011

FERRAZ, Cláudio Benito O. Geografia e Paisagem: entre o olhar e o pensar. Tese (Doutorado). São Paulo: FFLCH/USP, 2001.

GUERRA, Mariza. "Memória e cinema: diálogos abertos". Revista Presença Pedagógica, v. 18, $\mathrm{n}^{\mathrm{o}}$ 104, p. 71-79, mar./abr. 2012.

GUSMÃO, Milene de Cássia Silveira. Dinâmicas do Cinema no Brasil e na Bahia: trajetórias e práticas do século XX a $X X I$. Tese (Doutorado em Ciências Sociais). Salvador: UFBA/Faculdade de Filosofia e Ciências Humanas, 2008.

HALBWACHS, Maurice. A Memória Coletiva. São Paulo: Editora Centauro, 2006

LIPOVETSKY, Gilles, SERROY, Jean. A Tela Global: mídias culturais e cinema na era hipermoderna. Porto Alegre: Sulina, 2009.

MALDONADO, Simone. "Georg Simmel: uma apresentação”. In: Política e Trabalho, 12, set. 1996.

OLIVEIRA JUNIOR, Wenceslao Machado de. O que Seriam as Geografias de Cinema? (2006). Disponível em: < http://www.letras.ufmg.br/atelaeotexto/revistatxt2/wenceslao. htm>. Acesso em 20/10/2012. Não paginado. 
SANTAELLA, Lucia. "Palavra, Imagem \& Enigmas". In: Revista USP, São Paulo, v. 16, p. 36-51 dez./ jan./ fev. 19921993.

SANTOS, Milton. O Espaço do Cidadão. São Paulo: Nobel, 1987.

SANTOS, Myrian Sepúlveda dos. Memória Coletiva \& Teoria social. São Paulo: Annablume, 2003.

SCHAMA, Simon. Paisagem e Memória. São Paulo: Companhia das Letras, 1996.

SILVEIRA, Flávio Leonel Abreu da. (Org.). Paisagem e Cultura: dinâmica do patrimônio e da memória na atualidade. Belém: Ed. da UFPA, 2009.

\section{Filmografia}

A Grande Feira. Direção: Roberto Pires. Duração 91 min e 29 seg. Gênero: Ficção. Salvador-BA, 1961. 